\title{
Realizing Wedding Imaginations in South China
}

\author{
Eric K. W. Ma
}

This is a comparative case study to examine visuality in modern weddings in South China and its role in exhibiting and stabilizing social identity. By studying four wedding cases, I want to spell out the logics of visualization of wedding imaginations along three overlapping vectors, namely, visual competency, urban experience, and economic capital. The cases indicate that those with low visual competency, limited urban experience, and low economic capital tend to have a strong and hierarchical—or what I termed "high grid" — wedding imagination; while those with high visual competency, sophisticated urban experience and high economic capital have a more flexible and situational display of wedding visuality.

\section{THREE VECTORS}

This is a comparative case study ${ }^{1}$ to examine the visual elements of the modern wedding in South China and their role in exhibiting and stabilizing social identity. By studying four wedding cases, I want to spell out the different visualizations of wedding imaginations along three overlapping vectors. The first vector is the spectrum along the poles of rurality and urbanity. I am interested in how rural migrants who work in urban centers visualize their weddings and realize their imaginations. The second vector is visual competence, which affects the desire for and the ability to manipulate visual spectacles in wedding rituals. The third vector is economic capital, which restricts or encourages the realization of dreams and fantasies. The three vectors overlap. Urbanized individuals may have a higher chance to be more sophisticated in using visual language and have more economic capital. However, these vectors are not necessarily tied together; there are urbanites whose life-style preference is minimalist or pragmatic, with limited exposure to and weak desire for sophisticated visuality. These vectors are analytically distinctive and significant because they indicate and differentiate the various interlocking processes of cultural imagination, social practices, and social hierarchy.

ERIC K. W. MA is Head and Associate Professor, Communication Division, Graduate School, at The Chinese University of Hong Kong. He is the author of Culture, Politics and Television in Hong Kong and several books in Chinese on the popular culture of Hong Kong. E-mail: b-682790@cuhk.edu.hk 


\section{IMAGES OF THE MODERN WEDDING}

Wedding ritual, as a display of social relations and cultural desires, has been studied in historical, social, and anthropological terms. Some historical studies tend to focus on the ritualistic consolidation of traditions and the trends of marriage and family in the transition from traditional society to modernity. ${ }^{2}$ Some social studies focus on the transformation of intimacy in modernity [Giddens 1992] and the functions of marriage in social cohesion [Collins and Coltrane 1991]; others see wedding visuals as expressions of social status [Bourdieu 1984, 1990]; while anthropological studies focus more on the rites of passage which mark individuals' adulthood and new familial membership [Van Gennep 1960]. Of course, these disciplinary differentiations are rough, and recent academic discussions of the wedding are often interdisciplinary, involving comparison across different cultures in the context of global modernity and postmodern hybridization [Adrian 2003; Browning 2003]. In this article, I want to focus on the interplay between well-studied concepts such as urbanity and social status and the less examined factor of visual competence in wedding rituals. Previous studies on wedding rituals, crudely generalized above, have not been focused particularly on visuality. There are studies seeing dramatic wedding visuality as compensation for a fading familism [Sontag 1977] and unfulfilled womanhood [Adrian 2003]. In this study, I want to pay more attention to the contour of wedding visuality and its relation to economic and cultural capital.

Cultural capital, as explicated by Bourdieu [1984], is a stabilizer of the social hierarchy. It is a "softer side" of cultural differentiation, which forms a complement to the "harder side" of social differentiation by economic capital. Visual competency can be seen as a special aspect of cultural capital. Visual competency, in displaying visual markers, has become the conspicuous means for identity construction in the modern society of anonymity [Frosh 2003]. It is the ability to use visual means to make identity and life-style differentiation. Visual capital is acquired by the exposure to visual resources and the application of visual manipulation. It is related to urbanity, cosmopolitanism, and of course economic capital. Urbanity and cosmopolitanism, with high density and diversified information flow, are conducive to the development of a higher level of visual competency. Economic capital also provides the purchasing and consuming ability of exotic and/or technological visuality. However, visual competency does not necessarily correspond to the vectors of economic capital and urbanity. Somehow, visual competency is related to creativity and idiosyncrasy. Besides, those with extensive urban experience and high economic capital may wish to acquire cultural capital such as certificates and conspicuous status-conferring hobbies instead of visual sophistication. Adopting Hall's argument, ${ }^{3}$ visual competency has neither "necessary correspondence" nor "necessary non-correspondence" with economic and urban experience. Thus, my aim in this paper is to compare four theoretically generated samples, which exhibit a high level of case contrast in sociological terms, and bring the visual factor into the comparison. Traditional factors such as social and economic status are still the most significant factors in determining the contour of wedding imaginations. My focus on visuality is not intended to downplay these factors but to bring visual spectacles into the analysis. 
Cultural imagination, fueled by the media, propeled by the desire of life betterment, and hybridized by trans-border exchanges, has been a driving force for social mobility and migration. The visualization and actualization of cultural imaginations are also a social display and a declaration of achievement in the life politics of urbanites. This rising visual culture should be seen in the context of the transition from traditional to modern society, which involves the processes of detraditionalization [Thompson 1995] and individualization [Beck and BeckGernscheim 2002]. Life trajectories, or "do-it-yourself biographies," as Beck and Beck term them, are no longer tightly fixed by traditions, but are increasingly shaped by global forces and individual decisions.

Although these life trajectories are not as fluid as popular postmodernists would claim, they are a result of individual reflexivity, which is the constant self-monitoring according to the increasing knowledge of ourselves and of today's world. This reflexivity incorporates cognitive reasoning and emotive valorization. Cognitive reasoning is knowledge-based, while emotive valorization is related to media imageries and cultural imaginations, which are associational, impulsive, and visual. Popular images, serving as anchors of cultural imaginations, fuel desires, activate life-projects, and symbolize status. This article attempts to go beyond the general claims of the importance of visuality in high modernity and get into the internal logics of visuality in social practices. Wedding rituals, being among the most important personal and family events, can be used as a case for examining the interplay between visuality, cultural imagination, and social realization.

\section{CONTEXTUALIZING SOUTH CHINA}

South China was and still is the "window on the world" for most mainland Chinese. Historically speaking, because of geographic proximity to the outside world, the people of South China were more receptive to foreign ideas and pragmatic in dealing with cultural exchanges. They were ideologically more flexible and culturally less rigid. These cultural specificities still ring true nowadays. Within South China, there are huge gaps between the rich and the poor, the rural and the urban. Adding to these cultural and economic polarities, Hong Kong, originally an integrated part of the region, had been separated from the mainland culturally to become a highly consumerist and modern cosmopolitan locality under earlier British colonial rule. In the 1980s and the 1990s, Hong Kong was a "satellite" site of Western modernity, through which mainland Chinese could relate to the Western world [Ma 2001]. After her return to Chinese rule in 1997, Hong Kong has been reintegrated into this regional economy and has rediscovered her social and cultural ties with mainland China [Ma 2000]. However, there are still visible differences in terms of life-styles, values, and social practices between mainland China and Hong Kong. In this particular social context, I have selected four cases which can maximize the differential effects of various social and cultural factors under consideration here. Case A is the wedding of two "grassroots" rural migrant workers. Case B is the wedding of one mainland woman and an educated Hong Kong man. The couple of case $\mathrm{C}$ are a mainland 
photographer and a Hong Kong lower middle-class copywriter. Case D is a very successful middle-class couple in nearby Guangzhou. The couples in these cases are different in terms of their visual competence, social position, and urban experience. Methodologically speaking, Case A was ethnographic, and I did participant observation during the marriage negotiation; the wedding of Case B was participated in by my research assistant who was a friend of the couple. Cases $\mathrm{C}$ and $\mathrm{D}$ are documented basically by the method of life history interviews. ${ }^{4}$

\section{CASE 1: HYBRIDIZED WEDDING IMAGINATION}

The first case is the wedding of Mr. and Ms. A (named A for easy recognition and anonymity). Aged 27 and 24, respectively, Mr. and Ms. A are migrant workers who came from rural areas in Guangdong. They have been working in factories and construction sites in Guangzhou and Shenzhen for over five years. With the help of Hong Kong relatives, Mr. A has recently secured a supervisory job in a factory at Shenzhen. There he met Ms. A, who was a worker in a nearby factory. Ms. A was pregnant, and Mr. A went to her home village to propose. I went with the couple on that trip which took eight hours of travel in a van from Shenzhen to a remote village in the northeastern part of Guangzhou. The village is probably one of the poorest in Guangdong province; most of the villagers are farmers. I also paid a few visits to Mr. A's home village, which is also very poor. There is no public transport in either village. People move in and out on muddy roads by means of small private cars, motorcycles or bicycles. Restricted by poverty, physical and social mobility are difficult.

In China, migration is not just a possibility but also a compulsion for the rural poor. Massive migration from rural areas to urban areas, from the north to the south, from the inner cities to the coastal lands, has been one of the significant social changes in China since the 1990s [Lin 1997; Logan 2002]. As China is catching up with modernity, while overseas capital, ideas, information, technology, and people rush into China for her larger markets and lower costs, many Chinese are also pursuing their version of modern life by migrating to urban centers. Mr. and Ms. A are both from a rural and underdeveloped socioeconomic location. Their strong aspiration for an urban and modern social status is expressing itself in many aspects of their everyday life. Having a prestigious wedding ceremony is one of these expressions.

During the marriage negotiation, the parents of both families were concerned with traditional rituals. They did not care about taking wedding photos and videos, which were beyond their imagination. The meetings were mostly on peripheral matters such as the whereabouts of sisters and brothers and the happenings in the city. Matters directly related to the wedding were briefly mentioned, mostly on how to get official documents done on time. Serious negotiations were done afterwards, between smaller parties of sisters and relatives. The mother of the groom was very concerned over the date of the wedding, while the parents of the bride were more concerned with the wedding banquet because the two home villages are far apart and the bride's family was worrying about transportation. And the couple was ignorant of what a "good day" was, astrologically. They spent more time in shopping for their new home in Shenzhen. 
The couple thought that taking wedding photos was a trendy and modern thing to do. However, they were not able to differentiate between different dress codes and prestige symbols. The only indicator was price, which could be decided quite automatically by their budget. They went directly into a small shop and made the decision within 15 minutes. It was an RMB 1,500 (about US\$ 200) package including indoor and outdoor shooting, make-up, and dress rental. The wedding suits include Chinese, Western, and Japanese styles. They were unable to differentiate among these styles and treated them as a collective of modern symbols. The images of a wedding were decontextualized and only seen as fun-to-do things for urbanites. The visual elements were more or less decoded in term of visual pleasures, something dramatic that pleased the eyes. The couple, with a low level of visual competence and limited urban experience, was not subscribing to the subtle layers of visuality in wedding romances and myths.

On the day of the wedding, the groom's mother was working very hard to make the traditional rituals right. One interesting thing was that even the mother, who is in her late 50s, did not know exactly what to do. She did not know how to burn the offering at the Ancestral Hall. In fact, it was an old woman who taught the group what to do there; she is a neighbor in the village but not a member of the family. There were traditional visual spectacles in the ritual. For example, the couple were asked to step across a bowl of burning offering papers before entering the house. The rented white Western wedding gown was the most eyecatching element. Since the price for the wedding photo package included the gown rental for the day, the bride wore it all the way. On that day, the groom wore a new shirt. He specifically asked for a Hong Kong brand "Gold-Lion," which cost RMB 500 (about US\$ 67). The price of an ordinary shirt at the local market can be lower than RMB 50. He said that only the Hong Kong brand Gold-Lion has a quality guarantee. However, he finally bought a pirated GoldLion shirt for RMB 100, because the genuine shirt was just too expensive for him. Because of the couple's low economic status and undemanding yet keen desire for modern visuality, they were satisfied with superficial visual dressing for their own wedding.

On the wedding morning, the couple were following orders from the groom's mother and the old woman at the Ancestral Hall. The bride was in her eyecatching wedding gown and the groom was in his pirated Gold-Lion. They were supposed to be offering incense reverently. However, the couple did not pay much attention and kept on talking over the mobile phone or playing a handheld video game. In fact, the groom was on his mobile phone nearly all day. Inside the ancestral hall, the wedding ritual was comprised of traditional symbolism, paradoxical Western/modern dress codes, and new communication technology [Figure 1]. These ironic visual elements were displayed in a rural context, in which a general, superficial, and hybridized visuality of Western imagination could give onlookers a strong and prestigeful impression. They served as identity markers and symbols of detraditionalization and modernization. In the eyes of the relatives, these visuals marked the couple as urbanized and modernized individuals who had been freed from the confines of Chinese traditions.

In similar Chinese villages, wedding banquets are usually held at the ancestral hall (as of the early 2000s), which is an open and public space connected to the 


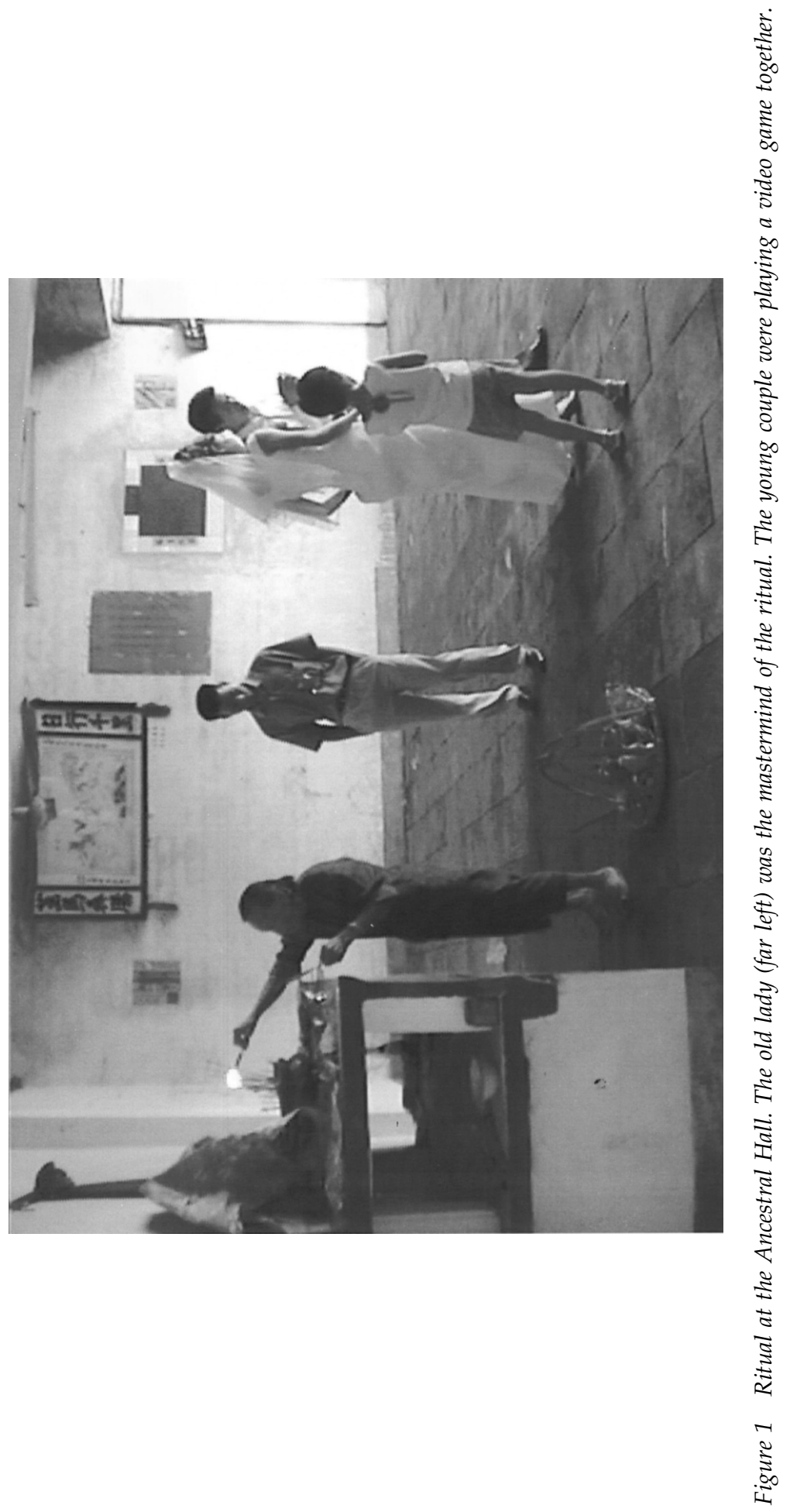


homes of relatives and friends. Guests pop in and out during the banquet. This type of arrangement is not expensive; the major expenses are for food and maybe hiring a cook and a few helpers. If the budget is tight, the banquet can be prepared and served by relatives and friends. After a brief argument, Mr. and Ms. A chose to hold the banquet not in the Ancestral Hall but in a restaurant in a nearby town. This arrangement is more expensive and considered more prestigious. Guests from the bride's family were taken to the town by a coach. The banquet was quite chaotic because many relatives behaved somewhat like they were attending banquets at the Ancestral Hall. They were moving around smoking, chatting, playing cards, without even bothering to greet the hosts. One of the waitresses complained to my research assistant that the guests were too rude and impolite. "I have never seen such terrible country bumpkins," she said. I had been to both kinds of banquet-those in the village Ancestral Hall and those in a small town restaurant. The manner of the guests in Mr. and Ms. A's wedding was no different from those who were at other village banquets at the Ancestral Hall. I did not have a feeling that the guests spitting and smoking at the Ancestral Hall were "dirty" and "rude." However, their "rudeness" was very conspicuous in the setting of the restaurant.

Interestingly, the bride's wedding gown and the digital video camera of my research assistant were also very conspicuous. These Western and modern icons attracted a lot of attention among rural guests. My research assistant replayed some of the footage he taken earlier at Mr. and Ms. A's wedding photo-taking session. When the guests watched the clip in which the couple wore different styles of wedding gowns and suits, they were very excited and commented that the couple looked really great and "advanced." They were not able to comment on the specifics, but the visuality, as a whole, conferred the aura of being superior and more advanced than the villagers. This modern visuality is an expression of remote imagination. Its meaning and contours are undifferentiated and the social actors and spectators were ignorant of the differences in the status hierarchy of a Western wedding. In this particular case, those "Western" and modern icons dramatized Mr. and Ms. A's disrespect for the village traditions and were used to inflate the difference between rurality and urbanity.

\section{CASE 2: "HIGH GRID" WEDDING IMAGINATION}

Mr. B was a Ph.D. student in Hong Kong at the time of the wedding. Although he was going to get a degree in mathematics, he was not optimistic about securing a job, because the job market in the academic field in Hong Kong is very competitive. He indicated that, even if he did get a job, it was not going to be a well-paid one, especially for a graduate in pure mathematics. Ms. B is a mainland woman whose family runs a small business in China. Her family is neither poor nor very well off and can be positioned in the lower middle class. As the eldest daughter in the family, she had to work and support the family in her high-school years. At the time of the marriage, she was in her late 20s and was considered "a bit too old" for mainland women. 
We attended the brief but formal ritual of the wedding, held at the Hong Kong Marriage Registration Office, and interviewed the couple afterwards. In the interview, the bride repeatedly said that although the groom was not good-looking and was quite poor she was proud of him, because he is an intellectual and he is from Hong Kong. Her relatives were all satisfied with the marriage. She said she would very much like to have had a higher education but could not because she had to take care of the family. The wedding of her younger sister, who had married before her, was financed and masterminded by her. It was elaborate and luxurious, with a parade of 20 expensive rented cars and a big wedding banquet. During the interview, she expressed a strong desire to have a wedding with a big and fanciful spectacle. Modern visual spectacles, such as big cars and an elaborate Western-style wedding gown, to her are symbols of success and prestige. For Ms. B, taking wedding photos is a must. Mr. and Ms. B took their wedding photos in a studio located in the bride's hometown in mainland China. They held a small wedding banquet there. If they had more money, Ms. B would have liked to have an extravagant wedding ceremony like her sister's. However, she spent most of her money for her sister's wedding, and Mr. B could not afford an expensive ceremony. The Hong Kong man, Mr. B, was not so eager to fulfill these cultural dreams, but was more concerned with fulfilling the wishes of his wife because he thought that he was not good enough for her. We asked what was the most memorable moment of the wedding and Ms. B said that it was the moment when the photographer at the studio clicked the camera and the bulb flashed before her eyes. It froze the moment and "completed" the marriage, she said.

With some urban experience, a little bit of lower middle-class economic capital, and fair visual competency, the bride developed a wedding imagination which I would characterize as "high grid," borrowing a term used by Douglas [1970, 1978]. Mary Douglas used the term to describe the configuration of social groups. Grid is high strength whenever roles are distributed on the basis of strong social classifications. I use the term here not to describe social configurations but to suggest the rigidity and power of cultural configurations. High grid cultural imagination refers to a rigid hierarchy of imageries in the mind of a social actor. The hierarchy of the cultural imagination is mapped onto the imagined social classes in which the social actor positions himself and others. In other words, those with a high grid cultural imagination have a relatively rigid sense of what cultural style should correspond to which social status group; he or she has a strong sense of upward mobility and a strong desire to live up to the aspired sociocultural position.

For Ms. B, the visualization of cultural imagination is a very significant element of the wedding. The bride had been trying very hard to realize those imaginations as long as the budget allowed it. The contour, or "grid," of visuality is rigid, elaborated, fine-tuned, natural, and thus mythic. The visuals serve as a bridge to make-believe a partial achievement of aspired social status. Unlike the rural migrants Mr. and Ms. A, who do not have the ability to discern subtle differences in urban imageries, Mr. and Ms. B, as lower middle class urbanites, can discern the fine contours of wedding imageries. However, Ms. B also has a strong sense of lack because of her inferior self-positioning as a mainland woman without a 
higher education. The cultural lack and the vivid cultural imaginations combined to foster a strong desire to realize a sophisticated wedding.

\section{CASE 3: PRAGMATIC BUT LUXURIOUS WEDDING IMAGINATION}

The third case is the wedding of a female accountant and a male architect in Guangzhou. Both of them are university graduates and very successful young urban professionals in their mid-20s. They are already owners of two flats, which is considered being quite well-off among their peers. Mr. C is a local Guangzhou urbanite, while Ms. C's parents are living in the rural area of a northern part of China. The bride's family has been converted to Christianity for many years and has abandoned most of their traditional religious practices. The major wedding negotiation between the two families was on religious rituals. At first, the bride's parents were reluctant to have a non-Christian son-in-law. Mr. C won the consent of the bride's parents by being very cooperative and obedient all along.

The wedding was planned and arranged according to the wishes of the bride's family. It took place at a famous historic church in Guangzhou. The whole ceremony was elaborate and very ritualistic. The church wedding ceremony was followed by a Western-style buffet lunch at a nearby five-star hotel. For most of the guests, the arrangements were quite usual. A Christian ceremony inside a church and a banquet in a hotel conferred a very trendy and elegant aura to the wedding. The arrangements were quite expensive and exceptional. However, the couple did this not as a display of social status but as a fulfillment of religious and parental expectation. The couple did not bother to go to a studio to take wedding photos even though they could afford it. They were not particularly attracted by the fancy images displayed at wedding studios. Mr. C is an architect with a high level of visual competency. Many of his friends are photographers and designers. One of his friends, Mr. D, whose wedding will be discussed below, is a professional photographer; and Mr. D took photos for the couple during the wedding. The couple believed that Mr. D's photography might even be better than that of hired wedding photographers.

When asked about their memorable moments, the bride said that she was moved by the first sight of the red carpet at the entrance of the church. "It seemed that the wedding was too real when I stepped out of the car and saw the red carpet and the magnificent hall of the church!" For Ms. C, a devoted Christian, the actualization of religious imagery completed the marriage. In contrast, Mr. C, an atheist, did not subscribe to the religious symbolism: "I was playing a game throughout. Like taking up a role. Like an actor playing a role. My utmost concern was to do exactly as they wanted and make no silly mistake." He mastered the whole wedding in a practical and efficient way. Even with the hotel buffet, he used it out of convenience because it is close to the church. Besides, having a lunch buffet was much simpler than having an elaborate Chinese wedding banquet. An interesting fact is that the memorable moment for the groom was the moment when they heard the sound of the official chop certifying their marriage at the Mainland Marriage Office. "Boom! And I told myself I was a 
married man." In China, the official wedding registration is very administrative, rationalized and demystified.

Both Mr. and Ms. C have extensive urban experience, high visual competency, and high income. For them, sophisticated visuality is not the only means to assert their upper middle class identity. They have many other ways to assert their superiority; so they did not take wedding studio portraits. The visual spectacle of the church wedding and the elegant hotel buffet were enough to stabilize the social relations within their social networks. The bride was attracted to religious symbolism, while the groom was very practical and treated the process with a strong instrumental rationality. For Ms. B, discussed in case 2 above, her "high grid" wedding imagination is a result of a sense of lack and a strong desire for upward mobility. Contrasting with a "high grid" imagination, Mr. and Ms. C have the ability to move along the "grid" of cultural imagination. To them, the visual styles of their wedding imagination are more pragmatic, luxurious, flexible, and unpredictable. They have more economic and cultural capital to juggle with and thus are less restricted to a rigid cultural grid.

\section{CASE 4: FLEXIBLE AND REFLEXIVE WEDDING IMAGINATION}

Case 4 is the wedding of Mr. and Ms. D, respectively, a mainland freelance photographer and a Hong Kong freelance writer. Our team stayed at their studio/home for three months to conduct a two-year participant research on the work-and-spend culture in South China. (The four cases discussed in this paper are a small part of this two-year project.)

Mr. and Ms. D met each other a few years ago when both of them were working for a design magazine. The magazine, based in Guangzhou, is owned by a Hong Kong company. In recent years, this Hong Kong company has relocated quite a substantial part of its publishing operation to China, thereby exploiting the cheaper salary rates in the mainland and bringing into China the more sophisticated and westernized design culture of Hong Kong. The company specializes in interior design of residential and commercial buildings. Mr. and Ms. D were responsible for photography and copy-writing, respectively.

Mr. D was born in Guangzhou; he grew up there and is working for the city government as a civil engineer. However, freelance photography is his main source of income. Mr. and Ms. D got married three years ago. Since Mr. D has been working in a government unit, they were allocated an apartment of 70 square meters at the time of their marriage. The couple put a lot of thought into the decoration of their home. They have a stylish open kitchen. Furniture is made of hardwood. Mr. D made the bookshelf and closet by himself. Most of the kitchen utensils were bought from Hong Kong. Ceramics and chopsticks carry Japanese and Thai patterns. There are several antique Chinese vases and teapots on the dining table.

Traveling and photography are Mr. D's hobbies. In 1998, he started shooting pictures for a magazine through the recommendation of one of his editor friends. Since then, he has been working as a freelance photographer for magazines, real estate companies and decoration companies. He still keeps his position at the 
government unit but has been more devoted to his freelance photography jobs. He did not get any formal training; however, the demand for photographers was so great that he could acquire the skills of professional photography by learning through working. His extensive experiences of working for various design magazines give him a higher visual competency than most of his peers. His wife was raised in Guangzhou and studied in a college in Hong Kong. She has extensive connections both in Hong Kong and in Guangzhou. Working as a journalist, freelance writer, and sales executive, Ms. D travels a lot and is knowledgeable in media and fashion trends both in mainland China and in Hong Kong.

Although the couple have relatively high cultural capital, they are at best in the low strata of the rising middle class in China. They earn around RMB 10,000 (about US\$1,350) per month, which is not bad at all but far lower than the salary of many of China's rising urban professionals. They are both quite sophisticated in term of visual competency and do not buy into the fantasy of elaborate visual dressing for a modern marriage. They grew up in the urban environment and do not have as strong a desire for upward social mobility as rural migrant workers like Mr. and Ms. A in Case 1. They exhibited a higher degree of flexibility in deploying visual elements during their wedding. Mr. D thought that wedding registration in China is too simple and dry, so they decided to do their official wedding registration in Hong Kong. They like the setting of the Hong Kong Marriage Registration Office. They said, "It is nice getting married in Hong Kong. The carpet, the saying of the oath, and the brief ceremony to be witnessed by a small group of friends and relatives ... In China, you go to the office in casual wear by yourself and it is like getting a driving license." In China, the wedding is disenchanted by bureaucratic rationality. So they picked Hong Kong to reenchant their wedding with a small dose of symbolism.

Ms. D wore a plain white gown, while Mr. D wore a formal suit at the wedding ceremony. They did not take studio portraits. Mr. D said he was still working on a freelance photo-taking job on the wedding day and did not have time to iron his wedding suit properly. "In a hurry, I almost ruined the suit with the hot iron," he said. The groom did not even wear a tie during the wedding [Figure 2]. When asked whether they regretted not having taken more "serious" wedding photos, the couple smiled and said they were happy with the wedding; if they had time they might retake a set of wedding photos, but they have been too busy since the wedding. We asked: "If you are to retake it now, what would you prefer? Still photo? Video? Western? Japanese? Or Chinese style?" "We don't want it too simple or too complicated. Going for outdoor video shooting will be too much for us. We definitely don't want those silly Japanese dresses and gowns!" With high visual competency, extensive urban experiences, and a lower middleclass income, they have a flexible wedding imagination and reflexive wedding practices. They said they might go for a more elaborate wedding if they had more money; but they were happy to have a simple and nice wedding at the Hong Kong Marriage Office, which is in a beautiful park. They did not have a strong urge to treat the wedding as a visual display of social status. They were very comfortable and confident about themselves even though they were not dressed up well enough during the wedding. Because of their sophisticated visual competence, a simple wedding visuality did not "hurt" their pride. 


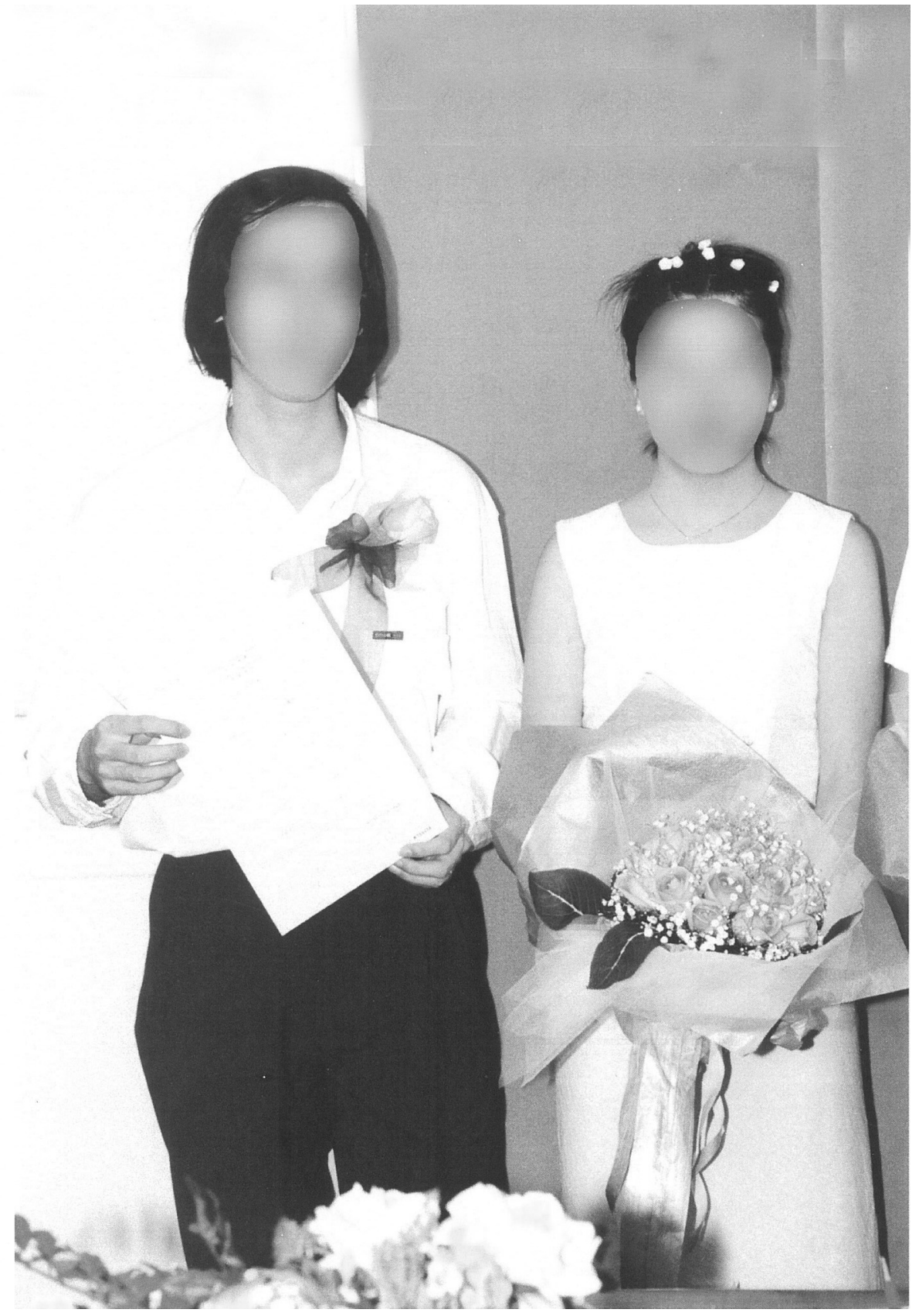

Figure 2 Photo taken after the ceremony at the Hong Kong Marriage Registration Office, the bride and groom in casual smart dress code. 


\section{CONCLUDING REMARKS}

As Giddens [1991] has indicated, in the transition to modernity, life becomes "lifeprojects"; biography becomes "do-it-yourself biographies". When people come into contact with new bio-references in media-saturated cities, they are more reflexive in contemplating the possibility of self-transformation. Not surprisingly, many urban myths in the cities of South China encourage this-a worker gets a fortune and opens his own business; a female worker perms her hair, puts on a pair of trendy jeans, and marries a rich man; an office boy works his way up to become a billionaire. To a large extent, these myths can be seen as a narrative of the collective desire for urban metamorphosis. " $\mathrm{I}$ " can become someone different. This is the consciousness of urbanity. Placing wedding rituals in this context of urban social mobility, realizing wedding imagination is one of the most significant and dramatic displays of individuals' life-projects. With different visual competency and economic capital, people realize different wedding imaginations and position themselves in different social hierarchies. In this comparative study, I have examined three interlocking factors in wedding rituals, namely urban experience, visual competency, and economic capital. By comparing these four cases, a few patterns can be generalized. For those with a low level of visual competency, with brief urban experience, and limited economic capital, cultural imaginations are vague but powerful. These cultural imaginations of the modern wedding are visualized and actualized in hybridized and chaotic codes; nevertheless, these hybridized visual codes confer social prestige on the wedding in a rural context. Looking at urbanity from a grassroots socioeconomic location, the wedding imagination can be described as "low grid" but high power. Low grid refers to the fuzzy, hybridized, and unsophisticated nature of the visual codes. These codes are powerful because they provide the cultural resources for the couple to imagine a better self-positioning, to break away from traditional rituals, and to assert their superiority among rural peers.

For those with some degree of visual competency, a brief urban experience, and lower middle class social positions, the power of cultural imagination is the strongest. For them, the visuality of the modern wedding is vivid, mythic, and elaborate. Their wedding imagination can be described as "high grid," which means they recognize a rigid hierarchy of what is culturally desirable and socially presentable. Because of a sense of cultural lack and a strong desire for upward mobility, these wedding imaginations become a visual plan for them to realize their life-projects. They will implement these visual plans as long as their budget permits.

For those with a high degree of visual competency, sophisticated urban experience, and high economic capital, they have a clear visual map of what a modern wedding is, but these plans are flexible because they have the cultural capital to deconstruct and reconstruct these wedding practices. Upward social mobility is achievable or has already been achieved. They do not have a strong sense of inferiority; neither do they have a strong urge to realize a fancy wedding in order to tell themselves and others of their achievements. For those with more disposable income, they are able to but may or may not opt for a more expensive wedding. Their visual tactics are more flexible and situational. 


\section{NOTES}

1. This research is supported by the Hong Kong Research Grant Council Earmarked Grant ref. $4318 / 01 \mathrm{H}$.

2. See Westermarck [1971] and Stone [1997].

3. Hall uses the phrase "no necessary non-correspondence" to describe the relation between the economic/material base and the cultural/ideological superstructure. See Morley and Chen [1996: Ch. 5].

4. This comparative case study is a small part of a two-year ethnographic research, in which I stayed in factories, discos, and other social gatherings and interviewed people on the rising work-and-spend culture in South China.

\section{REFERENCES}

Adrian, Bonnie

2003 Framing the Bride: Globalizing Beauty and Romance in Taiwan's Bridal Industry. Berkeley: University of California Press.

Beck, Ulrich, and Elisabeth Beck-Gernscheim

2002 Individualization: Institutionalized Individualism and Its Social and Political Consequences. London: Sage.

Bourdieu, Pierre

1984 Distinction: A Social Critique of the Judgement of Taste. London: Routledge. 1990 Photography: A Middle-Brow Art. Stanford: Stanford University Press.

Browning, Don

2003 Marriage and Modernization: How Globalization Threatens Marriage and What to Do About It. Michigan: Eerdmans.

Collins, Randall, and Scott Coltrane

1991 Sociology of Marriage and the Family: Gender, Love, and Property. (3rd edition). Chicago: Nelson-Hall.

Douglas, Mary

1970 Natural Symbols: Explorations in Cosmology. London: Barrie and Rockliff.

1978 Cultural Bias. London: Royal Anthropological Institute; Occasional Paper

Frosh, Paul No. 35.

2003 The Image Factory: Consumer Culture, Photography and the Visual Content Industry. Oxford: Berg Publishers.

Giddens, Anthony

1991 Modernity and Self-identity: Self and Society in the Late Modern Age. Cambridge: Polity.

1992 The Transformation of Intimacy: Sexuality, Love and Eroticism in Modern Societies. Stanford: Stanford University Press.

Lin, George

1997 Red Capitalism in South China: Growth and Development of the Pearl River Delta. Vancouver: University of British Columbia Press.

Logan, John

2002 Three Challenges for the Chinese City: Globalization, Migration, and Market Reform. In The New Chinese City. John Logan, ed. Pp. 3-21. Oxford: Blackwell. 
Ma, Eric

2000 Re-nationalization and Me: My Hong Kong story after 1997. Inter-Asia Cultural Studies, 1(1): 173-179.

2001 Consuming Satellite Modernities. Cultural Studies, 15(3-4): 444-463.

Morley, David, and Kuan-Hsing Chen, eds.

1996 Stuart Hall: Critical Dialogues in Cultural Studies. New York: Routledge.

Sontag, Susan

1977 On Photography. New York: Dell Publishing.

Stone, Lawrence

1997 The Family, Sex and Marriage in England 1500-1800. New York: Harper \& Row.

Thompson, John

1995 The Media and Modernity: A Social Theory of the Media. Oxford: Polity.

Van Gennep, Arnold

1960 [1909] The Rites of Passage. Chicago: University of Chicago Press.

Westermarck, Edward

1971 The History of Human Marriage. New York: Johnson Reprint Corp. 